\title{
Credit Systems for Bycatch and Biodiversity Conservation
}

\author{
Dale Squires $^{1 *}$, Rebecca Lent ${ }^{2}$, Peter H. Dutton ${ }^{1}$, Laurent Dagorn ${ }^{3}$ and Lisa T. Ballance ${ }^{4}$ \\ 1 Southwest Fisheries Science Center, U.S. NOAA Fisheries, La Jolla, CA, United States, ${ }^{2}$ International Whaling \\ Commission, Cambridge, United Kingdom, ${ }^{3}$ MARBEC, Univ. Montpellier, CNRS, Ifremer, IRD, Sète, France, ${ }^{4}$ Marine \\ Mammal Institute, Oregon State University, Newport, OR, United States
}

\section{OPEN ACCESS}

Edited by: Sunny Jardine, University of Washington, United States

Reviewed by:

Kate Mulvaney,

United States Environmental Protection Agency, United States Andrew M. Fischer, University of Tasmania, Australia Alan C. Haynie, National Marine Fisheries Service (NOAA), United States

${ }^{*}$ Correspondence: Dale Squires Dale.Squires@noaa.gov

Specialty section: This article was submitted to Marine Affairs and Policy, a section of the journal Frontiers in Marine Science

Received: 01 October 2020 Accepted: 16 April 2021 Published: 21 May 2021

Citation:

Squires $D$, Lent $R$, Dutton $P H$, Dagorn L and Ballance LT (2021)

Credit Systems for Bycatch

and Biodiversity Conservation.

Front. Mar. Sci. 8:613279. doi: 10.3389/fmars.2021.613279
Credit systems for mitigation of bycatch and habitat impact, incentive-based approaches, incentivize changes in fishery operator behavior and decision-making and allow flexibility in a least-cost method. Three types of credit systems, originally developed to address environmental pollution, are presented and evaluated as currently underutilized incentive-based approaches. The first, a cap-and-trade approach, evolved out of direct regulation through restricted limits with flexibility through the creation of tradeable unused portion of the limit, called credits. The second, a penalty-reward system, incentivizes bycatch- and habit-impact- reducing vessel behavior through rewards for positive behavior, and penalties for negative behavior. The third is a hybrid of the first two. All three systems can be used in the context of both absolute (fixed) and relative (rate-based or proportional) credits. Transferable habitat impact credit systems are developed for area management. The cap-and-trade credit system is directly compared to a comparable property rights system in terms of characteristics, strengths, weakness, and applicability. The Scottish Conservation Scheme and halibut bycatch reduction in the Alaskan multispecies groundfish fishery provide real-world examples of success with credit systems. The strengths, weaknesses, and applicability of credit systems are summarized, along with a set of recommendations. Cap-andtrade credit systems provide an important alternative to property rights, such as when rights are not feasible, and for this reason should prove useful for international fisheries. Penalty-reward and hybrid credit systems can substitute for cap-and-trade credit systems or property rights or complement them by addressing a related but otherwise unaddressed issue.

\section{Keywords: credits, bycatch, habitat impact, conservation, economic incentives, credit systems, property rights}

\section{INTRODUCTION}

Credit systems for bycatch and habitat impact conservation provide incentive-based approaches to reduce bycatch. Credit systems incentivize changes in vessel operator behavior and decisionmaking that allow them to flexibly reduce bycatch in a their own, least-cost way. Credit systems can be voluntary, as in the Alaskan pollock fishery (Bersch, 2013; Mize, 2014; Fina, 2017), or mandatory, as they were in the now superceded Scottish credit scheme (Curtis, 2017).

Three basic types of credit systems are defined in this paper, based on systems that were all originally developed to manage environmental pollution (Fischer, 2001, 2003; Montero, 2002; Boom and Dijkstra, 2009; Sovacool, 2011; Nentjes and Woerdman, 2012; Goulder et al., 2019). The first is direct regulation made flexible through a cap on Total Allowable 
Catch/Bycatch/Effort/Habitat Impact, shares of which are allocated to ${ }^{1}$ vessels to create vessel-level limits or quotas. ${ }^{2}$ The vessel's unused portion of the limit - the credit - can compensate the bycatch of a vessel beyond its limit, with the bycatch credit of another source, here the unused bycatch limit of another vessel. This trade in credits can be between vessels in a multivessel firm (internal source) or between independently owned vessels (external source). Credit exchange, whether in-kind or for monetary payment, creates a price in the "credit market," which can be implicit if formed through exchange between internal sources or explicit if formed in the secondary "credit market." Credits might also be banked for use in the next management year, depending upon the features of the program. This transferable credit (TC) system is a basically a cap-andtrade system.

Transferable credit management can be combined with price ceilings and floors in the credit market to form a two-part policy instrument, also called a hybrid policy instrument (Roberts and Spence, 1976; Pizer, 2002; Hepburn, 2006). ${ }^{3}$ The first part of the policy instrument is the TC and second part of the policy instrument is the credit price ceiling and floor. ${ }^{4}$ TC bycatch management was first proposed by Sugihara et al. (2009), and further discussed by Pascoe et al. (2010); Bersch (2013); Mize (2014); Van Riel et al. (2015); Lent and Squires (2017); Squires and Garcia (2018); Squires et al. (2018).

The second type of credit system is a two-part policy instrument that is a penalty-and-reward credit (PWC) system, also called an indirect tax-subsidy (Roberts and Spence, 1976; Fullerton and Wolverton, 1999, 2000, 2003; Segerson, 2011; Kotchen and Segerson, 2019). The first part is the penalty (indirect tax) and the second part is the reward (indirect subsidy). Deposit-refund programs are a familiar example, in which the deposit is the penalty and the reward is the refund (Bohm, 1981; Fullerton and Kinnaman, 1995; Fullerton and Wolverton, 1999, 2000, 2003). PWC has been discussed for bycatch by Segerson (2011); Van Riel et al. (2015), - who call it "behavioral credits, Kotchen and Segerson (2019) - who call it "behavioral credits," Lent and Squires (2017); Squires and Garcia (2018).

The third type of credit system is a three-part policy instrument, also a hybrid policy instrument. TC that are part of

\footnotetext{
${ }^{1}$ Bycatch can be broadly defined as unwanted species or individuals caught during fishing operations (Hall, 1996; Squires et al., 2021). Bycatch, from an economics perspective, can be classified as either a: (1) commercially exploited species with contributions to biodiversity and the ecosystem and its services that are not incorporated into market prices (i.e., incomplete market prices), or (2) protected species, also with contributions to biodiversity and the ecosystem and its services, but not commercially exploited or with a market price (i.e., without a market price - unpriced). A related problem is habitat impact, especially with groundfish bottom trawls, and more generally biodiversity. Hereafter, unless otherwise specifically noted, bycatch includes habitat impact whenever relevant, and the general points apply to the broad issue of biodiversity conservation through credit systems (e.g., habitat or water credits).

${ }^{2}$ In international fisheries, the Total Allowable Catch/Effort/Habitat Impact shares are invariably first allocated to States and then to the vessel (Grafton et al., 2010).

${ }^{3}$ Hybrid policy instruments differ from multiple policy instruments (Hepburn, 2006) by combining multiple policy instruments into a single instrument.

${ }^{4} \mathrm{~A}$ policy instrument is an individual economic tool which can be used to vary an economic parameter in order to achieve an economic objective. Hybrid instruments should be distinguished from the use of multiple instruments for the problem.
}

a cap-and-trade system are supplemented with penalty-reward credits (Weitzman, 1974; Roberts and Spence, 1976; Pizer, 2002). Adding penalty-reward credits to TCs creates additional flexibility and the ability to tackle additional issues that cannot be fully addressed by TC. For example, TC can address the overall level of bycatch but only with great difficulty and imprecision can TC by itself address juveniles or areas.

A limited amount of work has been done in fisheries on credit systems for bycatch (Pascoe et al., 2010; Segerson, 2011; Van Riel et al., 2015; Lent and Squires, 2017). Nonetheless, because credit systems have largely been developed in the literature on environmental pollution and to a lesser extent the economics of regulating industries (as noted in the references provided in the discussion), further insights can be drawn from environmental economics of pollution and industry. The PWC Scottish Conservation Scheme and the TC halibut bycatch reduction in the Alaska multispecies groundfish trawl fishery provide real-world examples of the effectiveness of credit systems in mitigating bycatch.

Section "Bycatch Credits" further develops the three types of credit systems for bycatch and habitat impacts. Section "Absolute and Relative Bycatch Credits" introduces absolute and relative credit systems, which are variations that can be applied to each of the three credit systems. Section "Habitat Impact Credits" introduces credits for transferable habitat impacts, which are separately discussed due to their distinct features as a separate type of bycatch. Section "Credits vs. Property Rights" discusses the difference between rights-based and credit management for TC. Section "Fishery Examples" presents two case studies. Section "Concluding Remarks" concludes this study.

\section{BYCATCH CREDITS}

This section develops TC, PWC, and the combined threepart approach, drawing from the environmental economics literature. Both TC and PWC can be implemented at the individual vessel, multi-vessel firm, broad industry level, where firms (single and multi-vessel) self-organize, or the individual State in an international fishery. Incentives are stronger the more directly the credit system is applied to bycatch. For example, a stronger incentive is created when applied to bycatch rather than target catch or effort. Incentives are created by establishing standards that limit the behavior of a producer, with a performance standard on the outcome of production, or a process standard on the process of production (see Helfand, 2013 for environmental pollution).

The three types of credit systems, since they derive from process or performance standards which are made flexible, can be uniform or differentiated by type of source, season, or even time of day (see Helfand, 2013 for environmental pollution). Thus, credit systems can be uniformly applied to all vessels or differentiated according to some criteria, such as vessel size class, bycatch species, gear type, area, season, habitat, Flag State, etc. If a single uniform standard is applied to all vessels, cost-effectiveness of each producer and by extension society as a whole will be undermined and therefore result in a less optimal outcome, given 
that vessels face different costs in meeting the uniform bycatch standard. As a consequence, bycatch reduction is more costly for each vessel, managers, and society as a whole.

Differentiated standards, which are more closely tailored to different classes of producers (e.g., vessel size classes, gear types), better fit the capability of heterogeneous producers (e.g., vessels of different sizes, gears, Flag States) to reduce bycatch at the lowest possible cost for that class of vessel. Differentiated standards thus tend to be more cost-effective than uniform standards, although transactions, information, and administrative costs (including enforcement) for the regulator may increase with the level of complexity. Differentiated standards are also less regressive in their distributional impacts, since standards are more directly tailored to individual producers. Direct regulation through differentiated standards can in principle achieve the same costeffective result of a TC but this would require that different standards be set for each pollution source, and, consequently, that policy makers obtain detailed information about the compliance costs each firm faces. Such information is rarely available to government. By contrast, market-based instruments provide for a cost-effective allocation of the pollution control burden among sources without requiring the government to have this information (see Stavins, 2001 for environmental pollution).

The TC has a Total Allowable Catch, Total Allowable Effort, or Total Allocable Habitat Impact which can be a hard cap or 'soft' cap. The goal could also be a vessel-level benchmark, based on a technological, scientific, or industry-specific bycatchtarget catch ratio rather than historical ratio (see Weishaar, 2007; Gerigk et al., 2015; and Goulder et al., 2019 for environmental pollution) or "yardstick" management, in which the bycatch of comparable vessels is used to infer a vessel's attainable bycatch level (see Shleifer, 1985 for environmental pollution and industry regulation). These approaches have largely been developed for and applied to environmental pollution, and are the basis of consideration as an incentives-based approach to bycatch mitigation. Under this approach, the vessel operator must account for every unit of bycatch in excess of the benchmark or "yardstick" and pay a penalty (monetary or in-kind) if the operator cannot attain credits via the trading system or benefit from its own past or future credit savings.

\section{Transferable Credits}

Under TC, a regulation obliges vessels to not exceed a limit, to have these limits accredited in some manner (including by third parties), and to report them to the regulator. While the regulator creates the rules and takes an active role in monitoring compliance, the regulator does not directly participate in the credit system. Vessels can buy new credits from, and sell their own credits, to other market participants. In a voluntary credit system, the regulator can be expected to have far less involvement, and may not even set an overall limit in a relative TC (although it would set the relative ratio). TC, in contrast to property rights, are not created by the regulator and distributed to vessels, although the flexibility to transfer the credits is facilitated by the regulatory framework and therefore a secondary market emerges for credits.

The TC price sets the basis for incentive-based management. The credit price raises the cost of production and the prices of target catch and bycatch that are landed and sold in commercial markets. Bycatch now has a market and a price, thereby creating a cost for bycatch that was formerly excluded from the cost of production. This includes bycatch of non-market bycatch, such as protected species, which now is also a cost that is absorbed by the target catch. The higher cost of production for both types of bycatch reduces the overall amount of bycatch and target catch produced (scale effect) and reduces the bycatch-target catch ratio (substitution effect). In the language of economics, the credit price internalizes the external cost of bycatch and thereby leads to a more socially optimal scale (volume) and scope (bycatch-target catch ratio) of production.

Transferable credit and PWC can incentivize real-time spatial management (Hobday and Hartmann, 2006; Little et al., 2015) and modified gear deployment to reduce the bycatch-target catch ratio. Real-time spatial management can be organized through a formal third party, such as Sea State in Alaska (Mize, 2014; Little et al., 2015), or internally within a firm through cooperation and communication (Fina, 2017). Credits can also create "dynamic" incentives to induce the creation and adoption of technological change that reduces the cost of production and the bycatch/target catch ratio - increasing "selectivity," i.e., bycatch reducing technological change (see Lent and Squires, 2017; Squires and Garcia, 2018; Milner-Gulland et al., 2018; Squires et al., 2018; for fisheries, and Montero, 2002 for environmental pollution).

Economic theory predicts that under TC, bycatch control measures will be concentrated in vessels that can do so at lowest cost (see Goulder and Parry, 2008 and Nentjes and Woerdman, 2012 for environmental pollution). Such vessels will earn credits and sell them at a profit. Vessels with high bycatch control costs then reduce costs by buying credits instead of controlling cost past some point whilst the costs of bycatch are fully reflected in their production costs and further down the marketing chain. Transferability creates gains from trade and the economic efficiency through the ensuing cost-effectiveness.

Credit markets can range from bilateral transactions between vessels, where vessels can be separately owned or owned by the same multi-vessel company, to a formal market between independent vessels. Credit market volume can also vary, depending upon fishery size and characteristics and the vessel's derived demand for credits and the vessel's supply of credits. A larger volume of credits is expected to lead to more stable prices, since individual transactions are smoothed out and each one is less influential. Greater market activity (i.e., credit formation and exchange) is expected during the end of the production period when bycatch limits begin to constrain production. Moreover, credit exchanges entail transactions and information costs, which can inhibit credit creation, exchange, and price signals that accurately reflect the value of a credit.

\section{Penalty-Reward Credits}

This is a two-part policy instrument, the first part of which is a penalty (indirect tax) on one market or non-market transaction such as catch, bycatch, or input (gear, equipment, days). The penalty can be in monetary units or in kind, such as units of catch, effort, or habitat impact. The penalty has a similar impact to a requirement that a vessel operator purchase additional quota 
from the regulatory body to cover any excess from the original quota. The penalty can be fixed in amount if the bycatch limit is exceeded or proportional to the amount by which the bycatch limit is exceeded (Segerson, 2011; Kotchen and Segerson, 2019).

The second part of this two-part policy instrument is a reward (indirect subsidy), either monetary or in-kind and fixed or proportional, on a different market or non-market transaction that is an alternative to bycatch with less adverse impact or an input or activity that reduces bycatch (Fullerton and Wolverton, 1997, Fullerton and Wolverton, 2000, 2003; and Kotchen and Segerson, 2019 for environmental pollution; Segerson, 2011 and Kotchen and Segerson, 2019 for bycatch). The tax and subsidy do not have to apply at the same rate, to the same species or input, or even to the same economic agent (vessel, firm). This type of credit system is a relative standard (process or performance standard), discussed in Section "Absolute and Relative Bycatch Credits" below, in which the indirect subsidy applies to vessels whose performance meets the standard or limit, whilst the indirect tax applies to vessels with performance or process exceeds the standard or limit. A deposit-refund system for Fish Aggregating Devices (FADs), penalty-reward bycatch credits, bycatch cap with fixed or proportional penalty/reward, or transferable credit markets with price ceiling and floor provide fisheries examples. A deemed value system for rights-based management is another indirect penalty-reward (tax-subsidy) (Squires et al., 1995).

This penalty-reward credits system can avoid the challenge of monitoring, enforcing, or measuring a direct tax (whether Pigouvian or "green") on bycatch (see Fullerton and Wolverton, 1997; Fullerton and Wolverton, 2000, 2003; and Kotchen and Segerson, 2019 for environmental pollution; see Segerson, 2011 and Kotchen and Segerson, 2019 for bycatch). This approach applies the penalty (tax) to observable market transactions, such as the purchase of target catch by a processor or even a consumer, and simultaneously to reward (indirectly subsidize) other market transactions, such as the purchase of "clean" inputs (e.g., subsidy to purchase bycatch friendly gear) or observable expenditures on non-market transactions such as operating expenditures for fishing in areas with lower bycatch. Even when it is possible to monitor and measure bycatch, enforcement may not be feasible. For example, a tax on bycatch may create a powerful incentive to reduce bycatch but it may also induce illegal discarding. The penalty reduces production and consumption of both bycatch and target catch (scale effect) and reduces the bycatch-target catch ratio (substitution effect).

The penalty is equivalent to a tax at the same rate on all inputs to production, such as vessel, gear, equipment, crew, fuel, bait (see Fullerton and Wolverton, 1997; and Fullerton and Wolverton, 2000, 2003 for environmental pollution; see Segerson, 2011 and Kotchen and Segerson, 2019 for bycatch). The penalty renders all bycatch-generating inputs relatively more expensive, and thereby reduces the bycatch-target catch ratio. The reward subsidizes all non-bycatching generating inputs, such as desired gear or resource stock in a fishing area. The first part is a tax that is imposed upon the presumption that all production uses a "dirty" technology. The second part is an environmental subsidy that is provided only to the extent that production uses "clean" technology.
The penalty does not have to equal the reward in order to effectively address bycatch (Fullerton and Wolverton, 1997, Fullerton and Wolverton, 2000, 2003 and Kotchen and Segerson, 2019 for environmental pollution; Segerson, 2011 and Kotchen and Segerson, 2019 for bycatch). A vessel operator could sometimes receive a reward and sometimes incur a penalty. On average and over time, if the penalties and rewards are correctly set and accounting for how the regulated fishery operators adjust to the policy, the quota should just be met and penalties should just match rewards (Fullerton and Wolverton, 1997; Segerson, 2011; Kotchen and Segerson, 2019). This matching of penalties and rewards implies that the policy would neither generate revenue nor require the regulator to raise funds to finance the rewards if denominated in monetary units. In the language of economics, this is revenue neutrality, and there are no net costs to vessels on average. Similarly, this matching implies that the regulator would not expend net in-kind credits or penalties on average over time.

Under certain bycatch situations, the magnitude of a fixed penalty can be set at any level high enough to ensure that the vessel has higher profits by complying with the target than not complying (Segerson, 2011). Under uncertain bycatch, such as rare-event bycatch, the fishery operator cannot avoid the penalty with certainty, and must instead weigh the marginal cost of bycatch reduction against the marginal expected benefit, which reflects not only the magnitude of the avoid penalty but the effect that additional bycatch reduction has on the likelihood of exceeding the target and hence imposition of the penalty. Thus, under uncertainty, the penalty must be set more carefully to ensure that this balancing leads to efficient bycatch reduction rather than too much or too little bycatch reduction. The combined penalty-reward approach treats randomly occurring outcomes symmetrically, imposing a penalty for exceeding the limit and a reward for being below it. Hence, despite the uncertainty about whether the allowable limit will be met given the firms' decisions, the limit itself does not affect producer incentives (Kotchen and Segerson, 2019). Such symmetry does not apply to the only a penalty or reward (based on a given threshold) but not both. Thus, combining the penalty with the reward ensures that even with uncertainty, private incentives align with social incentives, regardless of where the threshold is set. Segerson (2011) discusses the case of a proportional penalty under certain and uncertain bycatch.

Policy makers face many challenges in determining optimal penalties and rewards and in deciding whether to use in-kind or monetary units. A key factor is asymmetric information; policy makers hold less information about bycatch in contrast with the vessel operators. Uncertainty about the ratio between bycatch and target catch and economically optimal scale of production and how vessels respond to penalties and rewards further compound the difficulty in setting these penalties and rewards. In other cases, it may be difficult to determine the biologically optimal level of bycatch due to uncertainty around population estimates and 'rare event' bycatch species. The closer the penalties and rewards are calibrated to bycatch caught, the stronger and more accurate the incentive, however the more information is required. Whether the bycatch species is the limiting species to the catch of other 
bycatch and target species also impacts the difficulty in setting the penalty and reward.

Deposit-refund systems are most likely to be appropriate when: (1) the objective is one of reducing illegal or uncontrolled disposal, such as drifting FADs, as opposed to such objectives as general reductions in the level of bycatch or number of FADs and (2) there is a significant asymmetry between ex ante and ex post (post-deployment) clean-up costs (see Bohm, 1981; Bohm and Russell, 1985; Stavins, 2001 for environmental economics). For these reasons, deposit-refund systems may be among the best policy options to address disposal problems associated with gear and "ghost fishing."

An additional two-part policy instrument combines TC management with price ceilings and floors in the credit market (see Weitzman, 1974; Roberts and Spence, 1976; McKibbin and Wilcoxen, 2002; and Pizer, 2002 for environmental economics). Together, the credit price ceiling and price floor constrain the credit market to price positions within minimum and maximum bounds. This creates credit price stability. If the credit price stays at the floor, then the credit market becomes equivalent to a tax. Another two-part policy instrument entails an initial distribution of limits, accompanied by credit trading, combined with additional limits available from the management authority at a specified "trigger" price (see Roberts and Spence, 1976; and Weitzman, 1978; Pizer, 2002 for environmental economics). This approach combines quantity and price controls.

\section{Combined: Three-Part Policy Instrument}

Transferable credits that are part of a cap-and-trade credit system supplemented with penalty-reward credits form a three-part policy instrument (see Roberts and Spence, 1976; Weitzman, 1978; and McKibbin and Wilcoxen, 2002 for environmental economics). TC systems alone incentivize bycatch reduction, and the bycatch-reduction incentives and uncertainty are reduced by adding explicit penalties, such as loss of bycatch or effort quota, or rewards, including additional bycatch or effort quota drawn from an explicit pool set aside for this purpose, or a reward for catch below quota/baseline.

This combined approach addresses multiple issues (externalities) in a way that is not possible with a single approach. For example, TC can address the overall level of bycatch and when combined with a bycatch cap increases certainty. Adding penalty-reward credits enhances the ability to address additional issues such as juvenile target species bycatch or areas that are "bycatch hotspots." The combined approach can also incentivize desired adoption of bycatch reducing gear, gear deployment, and equipment. In principle, this three-part policy instrument combines the advantages of price-based (e.g., taxes) and quantity-based (e.g., quotas or limits) policy instruments and compensates for their deficiencies. A reward for adopting a bycatch reducing technology addresses the additional issue (externality) of sub-optimal technology. Three-part policy instruments do however incur greater monitoring and administrative costs.

A three-part policy instrument can also support formal or informal credit price floors and ceilings and thereby lower vessel risk and uncertainty. The penalty protects against unexpectedly high credit prices if true (marginal) bycatch reduction costs are higher than anticipated and therefore a pure relative credit trading system would result in bycatch reduction at a nonoptimal level. Rewards may stimulate further bycatch or habitat impact reduction if the marginal costs of bycatch reduction are lower than expected and a pure relative credit system would lead to too little conservation. The regulator pays vessels for every unit of bycatch that falls below their allowance (payments are typically in-kind, such as additional days). The reward sets a floor for the credit price, since any vessel with bycatch would rather collect this payment than sell credits on the market at a lower price. Within this price range, the credit program provides for satisfying the bycatch reduction target determined ex ante.

\section{Comparison of the Three Credit Systems}

The Table 1 compares the salient features, strengths, and weaknesses of the three credit systems.

\section{ABSOLUTE AND RELATIVE BYCATCH CREDITS}

Credits of any of the three types can be either absolute (fixed) or relative (rate-based, ratio, proportional) (see Helfand, 2013 for environmental pollution standards). Credit systems are implicitly or explicitly defined as a rate, such as per unit of time, per unit of input such as a FAD, per unit of area, or per ton of target catch. If the measure in the denominator of either the limit in a TC system (e.g., bycatch limit per time period) or the penalty-reward credit are completely exogenous to the process, any credit system can be considered an absolute credit system. An example is a bycatch limit of a specified number of animals per year. When a vessel has some control over the denominator, such as target catch in a bycatch-target catch ratio or input such as bycatch per day or per gear such as a FAD or number of bycatch animals per ton of target catch, the credit system is a relative credit system. Each compliance period, the regulator multiplies the total allowable bycatch by each vessel's bycatch ratio to obtain the allocation to each vessel (such quotas or limits in the denominator in relative systems are sometimes called intensity targets or rate-based standards in the environmental pollution literature: Weishaar, 2007; Nentjes and Woerdman, 2012; Helfand, 2013; Goulder et al., 2019).

Absolute credits entail an exogenous total and per vessel bycatch limit within each compliance period, but the total bycatch and the vessel allocations are endogenous with relative credits (see Goulder and Parry, 2008; Goulder et al., 2019; and Kotchen and Segerson, 2019 for environmental pollution). Unlike absolute credits, the regulator does not know the total bycatch and each vessel's bycatch until the end of the compliance period, after which vessel operators' production decisions over the period have been made.

The input for bycatch credits can be either directly related to bycatch reduction, such as gear, or a more general input such as days fished, with alternative impacts upon incentives and bycatch reduction. The input can be a stock variable, such as vessel size, or a flow input directly related to production, such 
TABLE 1 | Features, strengths, weaknesses of three credit systems.

\begin{tabular}{ll}
\hline Characteristics & Strengths \\
\hline $\begin{array}{l}\text { Transferable credits with cap-and-trade } \\
\text { Direct regulation made flexible } \\
\text { Allocate limits to vessels }\end{array}$ & $\begin{array}{l}\text { Creates incentives to lower bycatch } \\
\text { Substitute for property rights when rights are not suitable }\end{array}$ \\
Credit is unused limit & Fewer allocation issues than property rights \\
Transferable & More acceptable in many international fisheries than \\
Bycatch credits are priced to create & property rights \\
cost and economic incentive & $\begin{array}{l}\text { Flexibility to respond to changes in markets, environment } \\
\text { resource conditions }\end{array}$
\end{tabular}

Aggregate supply of credits not fixed but limit is fixed

Can be relative or absolute bycatch credits

\section{Penalty-reward (two-part policy instrument)}

First part: penalty (indirect tax)

Second part: reward (indirect subsidy)

Penalty and reward in money or in kind (e.g., days)

Penalty lowers bycatch by conferring a cost to bycatch

Reward lowers bycatch by conferring a benefit to bycatch reduction

Long-run revenue neutral

Deposit-refund

Transferable credits with cap-and-trade combined with price ceilings and floors

Can be relative or absolute

Economic efficiency, cost-effectiveness

Management authority controls aggregate bycatch limit

Minimal information requirements about vessels

Dynamic incentives for bycatch-reducing technological change

Creates incentives to lower bycatch

Avoids monitoring and enforcement problems of direct tax by applying tax to observable market transactions

Flexibility for regulator

Economic efficiency, cost-effectiveness

Welfare increasing (Pigovian) indirect tax and indirect subsidy

Dynamic incentives for bycatch-reducing technological change

Deposit-refund systems reduce lost gear, subsequent "ghost fishing," and overcapacity due to increasing gear productivity

Deposit-refund systems suitable when significant asymmetry between ex ante (legal) and ex post (illegal or post-deployment) retrieval or clean-up costs

Complements cap-and-trade property right or credit systems aimed at overall catch and overcapacity

Combined transferable credit and penalty-and-reward (three-part policy instrument)

Price controls combined with quantity controls
Creates incentives to lower bycatch

Allows addressing additional bycatch issues (externalities), e.g., age, area, timing

Combines advantages of both price- and quantity-based policy instruments

Can lower vessel risk and uncertainty by price ceiling and floor (form of insurance)

Dynamic incentives for bycatch-reducing technological change

Economic efficiency, cost-effectiveness
Weaknesses

Residual bycatch not priced or costed

Creates implicit output subsidy (no price or cost for residual bycatch)

Vessels do not incorporate residual bycatch cost into decision-making

Weaker incentive to reduce bycatch and lower efficiency than property right Weaker incentives for bycatch-reducing technical change than rights-based management due to lower costs and implicit output subsidy

Requires careful monitoring

High-grading and discards

Setting overall bycatch level

Rewards may not equal penalties in short run (not revenue-neutral)

Management authority does not directly control aggregate bycatch limit and mortality

High-grading and discards

Residual bycatch not priced or costed creating (implicit output subsidy)

Can reduce need to monitor and enforcement and thereby the associated costs

Relating optimal penalty and rewards to (optimal) bycatch fishing mortality complex

Setting optimal penalties and rewards for vessels requires vessel-specific information, creating uncertainty. Monitoring and enforcement needs (e.g., gear marking)

Setting overall bycatch level

Deposit-refund systems less suited for overcapacity and overfishing

Additional complexity and costs

Potential transactions and information costs, including asymmetric information between vessels and management authority

Residual bycatch not priced or costed (implicit output subsidy) 
as fishing time, with stronger incentives for bycatch reduction with flow inputs. ${ }^{5}$ Relative credits can also be defined in terms of a performance benchmark, such as a target bycatch reduction per vessel (cf. Weishaar, 2007; Gerigk et al., 2015; Goulder et al., 2019; and Kotchen and Segerson, 2019 in environmental economics) or a "yardstick" (cf. Shleifer, 1985 in the economics of regulation literature).

Reducing the relative credit's required ratio of bycatch-target catch or bycatch-input reduces bycatch. Similarly, tightening the relative credit's regulation ratio of bycatch per unit of input reduces catch. Over time, the regulatory body can adjust this ratio according to conditions in the environment, stock abundance, markets, experience, etc. The relative bycatch credit system, by which compliance requires avoiding exceeding a given ratio of bycatch to output or input, contrasts with the absolute credit system, by which compliance requires avoiding a given level of bycatch.

Absolute credits are likely to induce different bycatch conservation than relative credits because of the potential to change the denominator in relative credits. ${ }^{6}$ For instance, under absolute bycatch credits (such as a limit on the number of sea turtles caught), the vessel must reduce bycatch, the numerator. Under relative bycatch credits (such as the number of sea turtles per day/hook/or metric ton of swordfish caught), for example, the vessel can adjust the numerator by reducing bycatch or it can increase the denominator by increasing days, or more use of a gear, or increasing target catch (whichever is the denominator). An absolute bycatch credit program is unambiguous: bycatch must decline, but a relative bycatch credit program can potentially lead to ambiguous results - for example, as target catch increases, bycatch increases. The dependence of relative bycatch credits on within-period denominator decisions has important implications for incentives and associated system performance, affecting harvest levels, overall bycatch reduction, and the levels and distribution of costs (cf. Goulder et al., 2019 for environmental pollution).

Even if the denominator cannot be manipulated, the two approaches can differ in their effects if the denominator can fluctuate over time (Helfand, 2013 for environmental pollution). For example, bycatch per unit of target catch or some input (e.g., number of sea turtles per mt of swordfish or per hook) could fluctuate due to vessel breakdowns, spikes in fuel costs or plunges in target catch prices, bycatch species population levels, or even weather. In contrast, an absolute cap on bycatch (e.g., number of sea turtles) would not respond to such fluctuations.

The incentives generated by a relative credit defined as bycatch per unit of input (e.g., days or number of hooks) differ compared to bycatch per unit of target catch. Both reduce the observed bycatch-target catch ratio, but the prescribed bycatch-input catch ratio generates weaker incentives to reduce bycatch because the impact is less direct.

\footnotetext{
${ }^{5} \mathrm{~A}$ stock is measured at one specific time and represents a quantity existing at that point in time, which may have accumulated. A flow is measured over an interval of time.

${ }^{6}$ This paragraph extends Helfand (2013) discussion of (non-tradable, direct regulation) standards to credit systems.
}

Credit systems, either absolute or relative, with differentiated standards can help meet distribution objectives, since less stringent standards can be assigned to vessels that otherwise would face especially high compliance costs (Goulder et al., 2019). Multiple standards with absolute credits affect the distribution of policy costs but do not reduce cost-effectiveness. ${ }^{7}$ Multiple standards with relative credits increase the economic costs, thereby lowering cost-effectiveness, because they alter the relative magnitudes of the "implicit output subsidy" from unpriced residual bycatch across vessels and thereby distort the relative target catches of these vessels. Target catch levels may also be higher under relative credit systems, since the denominator (target catch or input level) in the bycatch rate is unconstrained. Hence, unit costs and revenues due to the scale of catch may differ between absolute and relative credit systems.

Another penalty-reward system with a relative bycatch standard arises when the (indirect) subsidy applies to vessels with performance better than (below) the standard, and the (indirect) tax applies to vessels with relative bycatch rates above the standard (see Parry and Krupnick, 2011; Goulder et al., 2019 in environmental pollution). ${ }^{8}$ In contrast with a relative transferable credit system, in which both the (indirect) tax and (indirect) subsidy apply to all covered vessels, such a system involves no "implicit output subsidy" from the unpriced residual bycatch to vessels that fail to meet the standard, and no tax on vessels that exceed the standard.

Due to the exigencies of sustainability and thereby absolute limits (performance or process standards), such as bycatch and target catch Total Allowable Catches, fisheries bycatch credit systems are invariably absolute rather than relative (rate-based). Nonetheless, relative credit systems could be applied when absolute limits are unavailable or unnecessary but the intent remains to reduce bycatch.

\section{HABITAT IMPACT CREDITS}

Transferable habitat impact quotas, first proposed as property rights (Holland and Schnier, 2006), can be extended to credit systems that can be applied to benthic habitat such as deep-water coral and sponge communities. Habitat impact in these cases is seen as one facet of the bycatch issue, but typically impacting a special type of species (e.g., cold-water corals and sponges) or the seafloor itself. Both of these unique features have sufficiently unique features to require separate and distinct discussion. The same basic economic principles of bycatch mitigation developed for bycatch reduction are applicable and developed here.

Transferable habitat impact quotas as a credit system directly address spatial management in a cost-effective manner. They can be combined with property rights or credit systems for catch (target, bycatch) or effort and technology standards

\footnotetext{
${ }^{7}$ Because an absolute TC program does not include the "implicit output subsidy" from the unpriced residual bycatch, the extent of standard variation across vessels (holding the total number of allocated limits fixed) does not affect a vessel operator's decisions at the margin (and thereby economic efficiency), and has only distribution consequences (see Goulder et al., 2019 for pollution).

${ }^{8}$ The environmental economics literature calls this approach a feebate.
} 
such as prescribed gear and its operation. ${ }^{9}$ They can be especially appropriate for gear such as groundfish trawls and scallop dredges that adversely impact the benthic habitat. They incentivize the use of skipper and industry-wide knowledge, unknown to the regulator, on a tow-by-tow basis. It can serve as an alternative to Territorial Use Rights for Fisheries (TURFs, Christy, 1982) - a form of spatial property rights, and provide a cost-effective alternative to permanent area closures such as Marine Protected Areas, or allow smaller and more tailored permanent area closures.

A transferable habitat impact quota credit system can be implemented at the industry or group level due to the complexity and cost of defining, observing, and enforcing habitat impact units allocated to individual vessels or even smaller groups of vessels, and indicators of group performance might be more easily monitored (Kotchen and Segerson, 2019). An industrylevel program also circumvents the issue of fractional units and rare events for individual vessels and allows self-organization and regulation. For example, one endangered species of coral has such a small population that the bycatch limit is less than one coral per vessel over the course of a year. Vessel Monitoring Systems can facilitate time/area enforcement by continually monitoring vessels' location and rate of movement thereby reducing costs of implementation. Group or industry approaches, in the face of limited information and uncertainty about the impact of individual vessel actions on habitat, can promote information sharing (Abbott and Wilen, 2010) and the pooling of risks across the individuals comprising the group (Holland, 2018; Holland and Martin, 2019; Kotchen and Segerson, 2019). Group or industry approaches can also allow the group to collectively devise and implement solutions, using lower information and transactions costs than individual approaches, for multiple issues. $^{10}$

Transferable credit can be applied in a cap-and-trade system with an aggregate cap - Transferable Habitat Impact, with the credit comprised of the unused portion of each vessel's or group's Transferable habitat impact quotas. Habitat impact quota could be held in reserve by the regulator. The world's first transferable habitat impact program was implemented as rightsbased management in British Columbia (Wallace et al., 2015; Driscoll et al., 2017). Such a program could be implemented as a TC program.

\footnotetext{
${ }^{9}$ In the language of economics, multiple externalities each require their own policy instrument unless the externalities are tightly linked. For example, overfishing of target species may be subject to individual transferable quotas and deep-water habitat may be subject to transferable habitat impact quotas.

${ }^{10}$ In the language of economics, a group approach can internalize multiple externalities, including the biodiversity and ecosystem service one of interest and vessel congestion. Group approaches can face moral hazard ("hidden action" and adverse selection ("hidden information") problems (Holland, 2018; Kotchen and Segerson, 2019). Successful groups may require homogeneous membership with well-aligned interests and/or formal contracts with monitoring and enforcement provisions and/or how the policy is designed (i.e., the rewards and penalties established by a specific policy) as well as the internal operating rules of the group itself. Without these conditions, non-compliance and free-riding may occur, in which one firm contributes more than its efficient level while the other firm contributes less (thereby free riding on the efforts of the other firm), and which contributes to economic rent and profit dissipation (Deacon, 2012; Kotchen and Segerson, 2019).
}

\section{CREDITS vs. PROPERTY RIGHTS}

Management by transferable property rights or absolute TCs, when both are cap-and-trade, ostensibly appear to be the same. Both allow maximum bycatch (right or limit) subject to the overall fishery cap (e.g., Total Allowable Catch/Bycatch/Effort/Habitat Impact with the option to buy or sell allowances (rights or credits). Such trade confers production flexibility and lower costs through reallocation of bycatch reduction activity, leading to vessels that can reduce bycatch at lower cost. Thus, vessels that more readily reduce bycatch and at lower costs can be expected to create and then sell credits to vessels with greater difficulty and higher costs of reducing bycatch. Both property rights and credits result in a market price for bycatch and therefore a reduction in bycatch as its cost is incorporated into production decisions. Due to the "implicit output subsidy," by which residual bycatch does not receive a cost so that remaining bycatch is not fully costed, TCs are less cost-effective for each vessel and society as a whole than rights-based management (Fischer, 2001, 2003); this is more fully discussed below.

Rights-based and absolute TC bycatch management differ along several dimensions. (This discussion is based upon Goulder and Parry, 2008; Boom and Dijkstra, 2009; Sovacool, 2011; Nentjes and Woerdman, 2012; Helfand, 2013; Goulder et al., 2019 for environmental pollution.) These dimensions are reflected as follows: (1) absolute TCs are direct regulation made flexible through credits that are not rights or entitlements but limits made flexible through exchange of unused portions (credits); (2) rights pertain to the entire limit or quota whereas credits refer only to the unused portion; (3) absolute credits are created gratis by producers but rights are created by the regulator or society; (4) under absolute TCs, residual bycatch is not priced and hence is free of explicit cost to the producer (giving the "implicit output subsidy"), whereas the residual bycatch under rights is always priced and hence given a cost to the producer (because the residual is property) that has an opportunity cost (value of next best alternative) because the unused right can always be sold; (5) the two systems differ with respect to economic efficiency, distributional impacts, and incentives for bycatch-reducing technological change ${ }^{11}$; and (6) aggregate supply of rights in any given year when a fishery cap is fixed but not for credits, although credit supply is limited by the annual fishery cap.

The property right in its entirety is both owned and transferrable, whether actually used in total or in part (for environment, see Goulder and Parry, 2008; Boom and Dijkstra, 2009; Sovacool, 2011; Nentjes and Woerdman, 2012;

\footnotetext{
${ }^{11}$ Under relative (rate-based) TCs, since compliance depends on a ratio (e.g., sea turtle bycatch per mt of swordfish or per thousand hooks), vessels can influence their allowance allocations by changing their output swordfish) or input (hooks) levels during the compliance period (see for environment, Helfand, 2013; Goulder et al., 2019). In contrast, under rights-based management or absolute TCs, a vessel's allocation of rights or limits (respectively) is not influenced by within-period production changes. The dependence under relative TCs of the limit allocation on within-period production decisions has important implications for incentives and associated system performance. It significantly affects production levels, overall bycatch reduction, and the levels and distribution of costs.
} 
Goulder et al., 2019). A credit only pertains to the unused portion of the limit, and does not entail a property right or entitlement to the entire limit, including the residual after the credit has been exchanged (Nentjes and Woerdman, 2012). TCs are complementary to direct regulation of bycatch and not a substitute, whereas rights-based management is a clear-cut substitute to direct regulation of bycatch.

Under TCs, both vessels entering the fishery or existing vessels receive mandated limits gratis, whereas vessels that exit or reduce bycatch lose the limits (see Nentjes and Woerdman, 2012 for environmental pollution). Under property rights, vessels typically receive rights gratis (although they can be auctioned or purchased from other vessels), and when exiting the industry or reducing bycatch, rights can be traded since they are property. Rights must typically be purchased when entering the fishery. Additional rights must also be purchased. The rights can be transferred and valued at the price from the rights market or as agreed upon between the vessels involved in the transaction. Both transferred and residual rights are valued at this price. The value of the residual rights forms an economic opportunity cost that the economically rational operator will incorporate into any profitmaximizing decisions (since it may be more profitable to lower the scale and scope of production and sell rights). Vessel exit does not diminish the quantity of rights held by multi-vessel firms, allowing greater reduction of fixed costs than under TCs and long-term consolidation of rights among fewer vessels.

Transferable credits do not directly place a price on limits, and therefore do not explicitly place an economic cost upon the residual bycatch that would be borne by the fisher (see from environmental pollution Goulder and Parry, 2008; Boom and Dijkstra, 2009; Sovacool, 2011; Nentjes and Woerdman, 2012; Goulder and Parry, 2008). TCs only prices the credit. The residual bycatch under the limit is neither a property right nor tradable. ${ }^{12}$ Because the residual bycatch remains unpriced, the impact upon vessel decision-making and behavior is weaker than property rights (Goulder and Parry, 2008). This is also a major reason why TC is less efficient than rights-based management, since as noted the latter prices and thereby confers a cost upon the residual bycatch (because of the ownership conferred upon the residual bycatch). This non-priced and non-costed residual is called an "implicit output subsidy" in the environment literature (Fischer, 2001, 2003). ${ }^{13}$

Under rights-based management, the residual impact cost that is added to the other costs of producing bycatch raises the average and marginal cost and price of bycatch (if it has a price) (Boom and Dijkstra, 2009; Nentjes and Woerdman, 2012; Goulder et al., 2019). The price of the target catch and bycatch incorporates this higher cost (due to the residual bycatch). The higher cost and

\footnotetext{
${ }^{12}$ Technically, the residual bycatch becomes private property from an unpriced common resource stock after capture. The absence of property here refers to an unpriced common resource that is not part of an allocated right to an amount of bycatch.

${ }^{13} \mathrm{~A}$ second type of implicit output subsidy arises with a relative standard rather than absolute performance or process standard (see Fowlie et al., 2016 and Goulder et al., 2019 for environmental economics). The relative standard, such as bycatch per unit of effort or target catch multiplied by the Total Allowable Effort or target Total Allowable Catch, increases the limits a vessel receives from the management authority and allows higher target bycatch.
}

price incentivize vessels to fish at the optimum scale for both target catch and bycatch and scope (bycatch-target catch ratio) of production. The vessel operator has internalized the external cost of bycatch. In contrast under TCs, although the price of the bycatch will reflect the variable costs of production, this price will not include the cost of the unpriced bycatch residual. ${ }^{14}$

In sum, average and marginal production costs under absolute (and relative) TCs should be lower than under rights-based management due to the "implicit output subsidy," i.e., the unpriced and uncosted bycatch residual, with only the credit receiving a price and cost (developed in the pollution literature, see Fischer, 2001, 2003; Boom and Dijkstra, 2009; Nentjes and Woerdman, 2012; Goulder et al., 2019). The uncertainty due to the expected shorter duration and lower security of the vessel's limit under credits, compared to rights, also raises average and marginal costs. Lower average and marginal costs of target and priced bycatch hamper the ability to be cost-effective and result in economically sub-optimal economies of scale - product volume and scope - bycatch-target catch ratio.

The "implicit output subsidy" of credits reduces the gains from trade, and hence lower costs, from credit trading (see Goulder et al., 2019 for the environment). Absolute TCs and rights-based management minimize vessels' costs by trading credits or rights until their marginal bycatch reduction costs equal the common credit or rights price. This maximizes the cost savings from trade, since in principle this trade equalizes the common credit or rights price across vessels. ${ }^{15}$ In sum, fleet-wide costs of a program with the same stringency and scope are lowest with rights-based management, followed by absolute credit systems and with highest costs relative credit systems due to the "implicit output subsidy," i.e., unpriced and uncosted residual bycatch.

Rights-based management creates stronger incentives for bycatch-reducing technological change than TC, PWC, or their three-part policy instrument combination. This is again due to the "implicit output subsidy" from not pricing residual bycatch and therefore not conferring a cost to the residual bycatch. In addition, the limit and hence credit is of more limited duration than rights-based management. Hence, with lower cost of bycatch and greater uncertainty over the duration, incentives to innovate and adopt bycatch-reducing technological change are weaker compared to rights-based management.

Table 2 summarizes the main points of the above discussion for absolute TC and transferable property rights.

\footnotetext{
${ }^{14}$ The difference in cost-effectiveness reflects the "implicit subsidy" to bycatch under TCs, which causes vessels' target catch output levels to exceed the levels consistent with minimizing the costs of achieving a given bycatch limit at would be achieved under rights-based management (see Goulder et al., 2019 for environmental pollution). Moreover, TCs are not expected to equalize marginal bycatch reduction costs across vessels even when credit trading is fully functional. This failure to satisfy the "equi-marginal principle" limits aggregate cost reductions from credit trades, because some vessels remain with higher costs than others, where trade would allow higher cost vessels to sell credits to lower cost vessels.

${ }^{15}$ Under relative TCs, a vessel minimizes its costs by trading credits until its marginal bycatch reduction costs equal the credit price (see Goulder et al., 2019 for the environment). This price generally differs across vessels, because it depends on bycatch reduction technologies that may be vessel-specific. This variation in technologies in turn prevents trading from equalizing marginal bycatch reduction costs across vessels, attenuating the gains from trade.
} 
TABLE 2 | Cap-and-trade absolute transferable credits versus transferable property rights.

\begin{tabular}{|c|c|c|}
\hline Feature & Transferable credits & Transferable property rights \\
\hline Initial allocation & Gratis, created by vessel, firm. & $\begin{array}{l}\text { Typically, gratis, but can be directly purchased by vessel } \\
\text { or firm from management authority or by auction. }\end{array}$ \\
\hline Entire versus residual bycatch & $\begin{array}{l}\text { Pertain to only used portion of bycatch limit but not } \\
\text { residual bycatch. Residual bycatch is not property } \\
\text { right, tradable, or opportunity cost of foregone } \\
\text { profits. }\end{array}$ & $\begin{array}{l}\text { Pertain to both used and residual bycatch. Residual } \\
\text { bycatch forms opportunity cost of foregone profits. }\end{array}$ \\
\hline Divisibility & Freely divisible. No impediment. & Freely divisible. No impediment \\
\hline Duration & Shorter, limited to one production period. & $\begin{array}{l}\text { Longer than one production period, often into } \\
\text { perpetuity. }\end{array}$ \\
\hline Transferability & $\begin{array}{l}\text { Pertains only to credit (unused portion of limit) but } \\
\text { not to residual bycatch }\end{array}$ & $\begin{array}{l}\text { Pertains to entire right, i.e., to entire amount of bycatch. } \\
\text { Rights can be traded since they are property. Additional } \\
\text { rights must be purchased. }\end{array}$ \\
\hline Gains from trade (arbitrage efficiency) & $\begin{array}{l}\text { Lower due to lower duration, lower volume of trade } \\
\text { (only credits), and failure to equalize marginal } \\
\text { bycatch reduction costs across vessels. }\end{array}$ & $\begin{array}{l}\text { Higher due to longer duration, higher volume of trade } \\
\text { (rent, lease, sell), and greater likelihood to equalize } \\
\text { marginal bycatch reduction costs across vessels. }\end{array}$ \\
\hline Exclusivity & Exclusive use to vessel or group allocated limit & Exclusive use to vessel or group allocated right \\
\hline Security & Same & Same \\
\hline Supply & $\begin{array}{l}\text { Endogenously created by vessel, firm. Depends } \\
\text { upon within-period production decisions. Overall } \\
\text { limit exogenously created by management authority. }\end{array}$ & $\begin{array}{l}\text { Exogenously created by management authority and } \\
\text { equal to overall limit. Does not depend upon } \\
\text { within-period production decisions. }\end{array}$ \\
\hline Production costs & $\begin{array}{l}\text { Lower due to residual bycatch without property } \\
\text { right or cost (implicit output subsidy) }\end{array}$ & $\begin{array}{l}\text { Higher since residual bycatch has property right and } \\
\text { cost. }\end{array}$ \\
\hline Strength of economic incentive to reduce bycatch & $\begin{array}{l}\text { Weaker, since lower costs of production due to } \\
\text { unpriced and uncosted residual bycatch (implicit } \\
\text { output subsidy) and shorter duration of credit and } \\
\text { limit }\end{array}$ & $\begin{array}{l}\text { Stronger, since higher costs of production due to priced } \\
\text { and costed residual bycatch and longer duration of } \\
\text { credit and limit. }\end{array}$ \\
\hline $\begin{array}{l}\text { Strength of dynamic economic incentive to innovate } \\
\text { bycatch-reducing technological change }\end{array}$ & $\begin{array}{l}\text { Weaker because of implicit output subsidy, lower } \\
\text { cost increase, and shorter duration of credit and } \\
\text { limit }\end{array}$ & $\begin{array}{l}\text { Stronger because entire bycatch is given a cost, hence } \\
\text { vessels have stronger incentive to innovate in order to } \\
\text { lower costs and longer duration of right }\end{array}$ \\
\hline Cost-effectiveness/efficiency & $\begin{array}{l}\text { Weaker, includes implicit output subsidy due to } \\
\text { unpriced and uncosted residual bycatch. Smaller } \\
\text { gains from trade. }\end{array}$ & $\begin{array}{l}\text { Stronger because entire bycatch receives price and } \\
\text { cost incentivizing vessels to reduce scale of production } \\
\text { and lower bycatch-target catch ratio. Larger gains from } \\
\text { trade. }\end{array}$ \\
\hline Entry/exit & $\begin{array}{l}\text { Entering or existing vessels receive mandated limits } \\
\text { gratis. Vessels that exit or reduce bycatch lose the } \\
\text { limits. }\end{array}$ & $\begin{array}{l}\text { With property right, all or part of bycatch can be traded } \\
\text { upon exit. } \\
\text { Vessel exit does not diminish the quantity of rights held } \\
\text { by multi-vessel firms. }\end{array}$ \\
\hline Relationship to direct regulation & $\begin{array}{l}\text { Direct regulation made flexible, and thereby } \\
\text { complement }\end{array}$ & Substitute to direct regulation \\
\hline
\end{tabular}

\section{FISHERY EXAMPLES}

\section{The Scottish Conservation Credit Program}

In response to declining cod stocks and the need to reduce bycatch in the Scottish trawl fishery under European Union regulation, the Scottish Conservation Credit Program (SCCP) started in 2007 after the European Commission implemented the second revision of the Cod Recovery Plan (Van Riel et al., 2015). This Plan required further reductions in fishing effort in North Sea cod fishing grounds. The European Union's full retention policy subsequently replaced the SCCP.

The SCCP combined private, voluntary solutions with direct regulation and incentive-based management through a compulsory absolute penalty-and-reward credit system (PWC) system to reduce cod (Gadus marhua) target catch in the Scottish North Sea mixed species demersal fishery and low-value cod bycatch from the Norway lobster (Nephrops norvegicus) fishery (hereafter all material is from WWF, 2009; Fernandes et al., 2011; Holmes et al., 2011; Scottish Government, 2011; Curtis, 2017). The trawl fishery operators were required to discard overquota and undersized cod, both perversely incentivized by the direct regulation quota. The SCCP aimed to allow fishing for other species while avoiding cod and reducing overall effort. The program allowed enough days for vessels to catch their quota while not increasing cod removals and thereby allow cod stock recovery.

The SCCP achieved bycatch avoidance through timearea closures and real-time spatial management triggered by monitoring the cod catch per hour of tow. Minimization of bycatch was achieved through optional and voluntary technology standards, notably gear (Orkney trawl, square mesh panels, "one net rule" that ensure only regulated, more selective gear is used) and operating requirements, such as the move-on requirement when the catch rate is exceeded, and post-interaction activities 
such as release alive. Some policy instruments were complements and some were substitutes. Over time, the aggregate Total Allowable Effort was progressively tightened.

The SCCP incentivized changes in fisher behavior and decision-making through an absolute PWC system, notably daysat-sea allocated each year as an annual limit, not as a property right for future years. Days eventually transformed from nominal days to kilowatt days-at-sea reflecting the relative fishing power of the heterogenous vessels comprising the fleet. Vessels with $<1.5 \%$ $\operatorname{cod}$ as a proportion of total catch were already exempt from days-at-sea limit. European Union capacity reduction and the Cod Recovery Plan created surplus days for rewards in the SCCP rather than explicitly retaining days from the Total Allowable Effort for rewards or relying upon penalty. There was no attempt to achieve neutrality by balancing penalty-and-reward days.

Penalties to incentivize avoidance and minimization of bycatch include lowering the vessel's balance of days to penalize non-compliance, including fishing in closed areas. Rewards include extra kilowatt days-at-sea to compensate for foregone catch created when vessels avoid cod-dense areas through voluntary real-time spatial management, using more selective gear, and more generally by demonstrating low cod catch. The SCCP further rewarded vessels through an allowance to use the days more flexibly, operating under hours- rather than daysat-sea, thereby inducing fuel conservation and more efficient operation and lower costs. Days could also be transferred between vessels, introducing elements of TC. Days were not consolidated on a fewer number of vessels with limited days per vessel.

The role of direct regulation was crucial. Although the PWC system created incentives, the direct regulation allowed the incentives to be effective. The Cod Recovery Plan immediately created an untenable situation due to cod quotas, and the hard limits for days annually declined from 330 to 180 , incentivizing participation in the SCCP. The SCCP would not have worked without effective monitoring (through Vessel Monitoring Systems, observers, on-board cameras, matching processor purchases to vessel sales, limited number of ports to land, logbooks) and enforcement.

\section{Halibut Bycatch Reduction in the Alaska Multispecies Groundfish Trawl Fishery}

The large-scale groundfish trawl fishery in Alaska is comprised of five companies and 18-22 catcher processors that receive target catch share allocations and is managed by two harvest cooperatives (Alaska Seafood Cooperative and Alaska Groundfish Cooperative) (Abbott and Wilen, 2010; Abbott et al., 2015; Little et al., 2015; Fina, 2017). The companies also receive prohibited species catch allowances for halibut, red king crab, snow crab, and tanner crab that are allocated by historical usage of targets rather than bycatch history, thereby avoiding the moral hazard problem of rewarding those with high bycatch history. The five companies cooperate by meeting a minimum of once per month and engaging in regular communications. Companies (vessels) could vest their shares in a cooperative formed by participating members. Cooperatives are internally managed and provided with considerable flexibility to internally allocate catch allowances.

The bycatch program for the prohibited halibut was initiated due to high rates of economic discards in a derby fishery that arose in response to the fleet-wide bycatch caps (Abbott and Wilen, 2010; Abbott et al., 2015; Little et al., 2015; Fina, 2017). The North Pacific Fishery Management Council directed the cooperatives to develop halibut avoidance plans. Through co-management, the Council established a voluntary bycatch performance standard with a limit and then let the industry devise its own way to satisfy the limit. Each cooperative sets a fixed tonnage halibut allowance based upon historical halibut catch. This allowance is distributed among its vessels based upon groundfish target allocations. Vessels must meet halibut bycatch rate standards based upon history in a relative bycatch performance standard of the ratio of halibut to groundfish. Each flatfish species has an annual relative performance standard.

Each cooperative defines best-practice halibut avoidance and minimization of bycatch (Abbott and Wilen, 2010; Abbott et al., 2015; Little et al., 2015; Fina, 2017). Bycatch avoidance and minimization are achieved by best-practice process and technology standards. The process standards for avoidance included fishing target choice of location and time of day to fish. The technology standards for minimization include small test tows when entering an area, halibut excluders, and deck sorting to quickly return halibut bycatch to the water. Excluders generate target catch losses (opportunity cost) and can obscure deck sorting once the net is emptied on the vessel. Avoidance was also realized through real-time spatial management using regular vessel-to-vessel communication, including weekly bycatch conference calls by captains (Little et al., 2015). Such communication was found to be faster and more effective than through the commercial company Sea State that collects information in the Alaskan salmon bycatch credit program in the Alaskan pollock fishery (Bersch, 2013; Mize, 2014; Little et al., 2015). Internal cooperative and vessel cooperation leads to faster communication.

"Yardstick" management (see Shleifer, 1985 for economics of regulation) is practiced for the relative PWC (with an overall cap). An annual test, based on historical targets ("yardstick") eliminates bycatch excess (Fina, 2017). Vessels must achieve halibut bycatch rates based on historical average fleet performance ("yardstick"), with rates decreasing across 3 years. Bycatch in excess of the "yardstick" incurs a monetary penalty of US $\$ 25,000$ - US $\$ 100,000$ per violation that escalates by the amount of target catch. A low catch threshold allows the vessel operator to avoid a penalty if bycatch is kept at low levels. Vessels can sell target quota to another vessel, which implicitly constitutes a trade of the relative bycatch-target catch-bycatch credit. There is in effect very little trade. Quarterly monitoring applies to vessels that fail an annual test. Halibut limit forfeitures without redistribution form another penalty. Reallocation would otherwise create moral hazard through a perverse incentive of discouraging communication.

The fourth quarter test applies an aggregate relative rate performance standard to all flatfish targets $(12.1 \mathrm{~kg}$ halibut per $\mathrm{mt}$ of groundfish), thereby addressing another moral hazard 
problem (Fina, 2017). Vessels approaching the end of the year with substantial amounts of bycatch quota would otherwise not face an economic incentive to maintain avoidance through the end of the year (in this case, the economic incentive's relative price effect overwhelms any intrinsic motivation held by vessels).

\section{CONCLUDING REMARKS}

Credit systems are a form direct regulation of target catch, bycatch, effort, or habitat impact through performance or process standards, implemented through limits or quotas made flexible. There are three fundamental types of these incentive-based approaches. The first, transferable credit systems, are cap-andtrade and create a price in the credit market. The first evolved out of direct regulation made flexible through the creation of unused limits - credits - with the option to compensate excess use of one source by excess control of another source. The second type of credit system incentivizes changes in fisher behavior and decision-making through penalties and rewards in either cash or kind for increasing or decreasing bycatch, respectively. This twopart policy instrument combines a reward (indirect subsidy) with a penalty (indirect tax). The third type combines the transferable credits and cap-and-trade with penalty-and-rewards to create a three-part policy instrument.

Credit systems, as incentive-based policies, are potentially cost-effective for producers and hence the fishery and society writ large. Credit systems can easily complement and incentivize adopting technology standards, such as required gear design and operating standards, and further advancements in bycatch reducing technological change. Bycatch credit systems can be either absolute or relative, the latter specified as the ratio of bycatch to target catch of a species or as the ratio of bycatch to an essential individual input such as gear or fishing time. Relative bycatch credit systems do not necessarily impede the continued growth of the relevant target species. Credit systems can be formed solely at the industry level, at the individual vessel level, or a mixture of both.

Credit systems are particularly promising when rights-based management is not possible. Without property rights, credit allocations are of limited duration, potentially revocable, with less at stake, and less uncertainty. Entry into the fishery is readily accommodated. Credit systems may be are particularly promising for fisheries in which multilateral coordination typically through consensual decision-making - is difficult to achieve with as "permanent" of a policy instrument as property rights. Hence, credit systems are potentially very promising for international fisheries. Credit systems price bycatch but do not price residual bycatch or habitat impact, creating the "implicit output subsidy," so that the resulting increase in costs due to batch is lower and the incentives are weaker than under rightsbased management.

The Scottish credit system illustrates how to successfully design a penalty-reward (indirect tax-subsidy) system centered around days-at-sea to incentivize avoiding bycatch and technology standards of gear design to incentivize minimizing bycatch. A crucial feature is the threat of more stringent direct regulation. The Alaska multispecies trawl system also illustrates successful application of the first type of credit system to incentivize bycatch avoidance and minimization. A crucial feature entails the application at the group level, with the fishery management authority providing overall guidance, monitoring, and enforcement. A second crucial feature entails allowing individual multi-vessel companies to reduce bycatch by internally reallocating credits within the company from a source able to successfully reduce bycatch at a lower cost than another source.

In sum, credit systems provide an incentive-based approach to bycatch reduction that can stand alone or complement other policies. Besides readily complementing technology standards such as gear and equipment requirements, credit systems provide additional flexibility and a means to address otherwise unmanaged components of direct bycatch regulation, such as time-area management. Credit systems can also complement capacity management that uses cap-and-trade credits or rightsbased management through penalty-reward credits for age and size-related issues not otherwise readily addressed by a property right or credit on catch or effort. Credit systems provide a credible, and in some ways superior, alternative to rightsbased management. Credit systems are generally superior to rights-based management in international fisheries and even national fisheries where resistance to rights-based management, or insurmountable difficulties in reaching agreement, limits their use. Although credit systems may be "second best" to rights-based management, they still provide improvements in bycatch reduction and economic benefits compared to a total absence of bycatch measures. When management authorities seek an alternative to direct regulation, credit systems offer a promising alternative, since they grew out of direct regulation made flexible and cost-effective. Credit systems may also serve as an intermediate step between direct regulation and rightsbased management. Finally, examples already in place in the environmental policy realm, such as cap-and-trade in carbon markets, can enhance the attractiveness of such measures in multilateral fishery management.

\section{AUTHOR CONTRIBUTIONS}

All authors contributed to the conception and writing of the manuscript and approved the submitted version.

\section{FUNDING}

Funding for salaries was provided by each authors' institution.

\section{ACKNOWLEDGMENTS}

The views expressed in this article are those of the authors, and do not necessarily reflect those of the US NOAA Fisheries, the International Whaling Commission, or Institut de Recherche pour le Développement (IRD). 


\section{REFERENCES}

Abbott, J. K., Haynie, A. C., and Reimer, M. N. (2015). Hidden flexibility: institutions, incentives, and the margins of selectivity in fishing. Land Econ. 91, 169-195. doi: 10.3368/le.91.1.169

Abbott, J. K., and Wilen, J. E. (2010). Voluntary cooperation in the commons? Evaluating the Sea State Program with reduced form and structural models. Land Econ. 86, 131-154. doi: 10.3368/le.86.1.131

Bersch, F. (2013). Report to the North Pacific Fishery Management Council on the 2013 Bering Sea Pollock Mothership Salmon Incentive Plan. Available online at: https://www.npfmc.org/wp-content/PDFdocuments/catch_shares/ CoopRpts2013/SalmSavingsIPA-313.pdf (accessed April 25, 2021)

Bohm, P. (1981). Deposit-Refund Systems: Theory and Application to Environmental, Conservation, and Consumer Policy. Baltimore, MD: Johns Hopkins University Press for Resources for the Future.

Bohm, P., and Russell, C. S. (1985). "Comparative analysis of alternative policy instruments. Chapter 10," in Handbook of Natural Resource and Energy Economics, Vol. 1, eds A. V. Kneese and J. L. Sweeney (Amsterdam: Elsevier Science Publishers), 395-460. doi: 10.1016/s1573-4439(85)80013-0

Boom, J.-T., and Dijkstra, N. R. (2009). Permit trading and credit trading: a comparison of cap-based and rate-based emissions trading under perfect and imperfect competition. Environ. Resour. Econ. 44, 107-136. doi: 10.1007/ s10640-009-9266-8

Christy, F. T. Jr. (1982). Territorial Use Rights in Marine Fisheries: Definitions and Conditions. Technical Paper 227. Rome: Food and Agriculture Organization of the United Nations.

Curtis, H. (2017). "Scottish credit system for cod," in Presentation to Workshop on Incentive-Based Bycatch Reduction Case Studies. Unpublished (Sète: NOAAIRD-Ifremer).

Deacon, R. T. (2012). Fishery management by harvester cooperatives. Rev. Env. Econ. Policy 6, 258-277. doi: 10.1093/reep/res008

Driscoll, J., Wallance, S., Turris, B., and Mose, B. (2017). "Using individual vessel quotas to manage coral and sponge bycatch: the case of the British Columbia groundfish bottom trawl fishery," in Presentation to Workshop on IncentiveBased Bycatch Reduction Case Studies. Unpublished NOAA-IRD-Ifremer, Sète.

Fernandes, P. G., Coull, K., Davis, C., Clark, P., Catarino, R., Bailey, N. R., et al. (2011). Observations of discards in the Scottish mixed demersal trawl fishery. ICES J. Mar. Sci. 68, 1734-1742. doi: 10.1093/icesjms/fsr131

Fina, M. (2017). "Alaskan groundfish trawl and halibut bycatch," in Presentation to Workshop on incentive-Based Bycatch Reduction Case Studies. Unpublished NOAA-IRD-Ifremer, Sète.

Fischer, C. (2001). Rebating Environmental Policy Revenues: Output-Based Allocations and Tradable Performance Standards." RFF Discussion Paper 01-22. Washington, DC: Resources for the Future.

Fischer, C. (2003). Combining rate-based and cap-and-trade emissions policies. Clim. Policy 3S2, S89-S103.

Fowlie, M., Reguant, M., and Ryan, S. P. (2016). Market-based emissions regulation and industry dynamics. J. Polit. Econ. 124, 249-302. doi: 10.1086/ 684484

Fullerton, D., and Kinnaman, T. (1995). Garbage, recycling and illicit burning or dumping. J. Environ. Econ. Manage. 29, 78-91. doi: 10.1006/jeem.1995.1032

Fullerton, D., and Wolverton, A. (1997). The Case for a Two-Part Instrument: Presumptive Tax and Environmental Subsidy. Working Paper 5993. Cambridge, MA: National Bureau of Economic Research.

Fullerton, D., and Wolverton, A. (1999). "The case for a two-part instrument presumptive tax and environmental subsidy," in Chapter 3 in Environmental and Public Economics: Essays in Honor of Wallace E. Oates, eds A. Panagariya, P. Portney, and R. Schwab (Cheltenham: Edward-Elgar), 32-57.

Fullerton, D., and Wolverton, A. (2000). Two Generalizations of a Deposit-Refund System. Working Paper 7505. Cambridge, MA: National Bureau of Economic Research.

Fullerton, D., and Wolverton, A. (2003). The Two-Part Instrument in a Second-Best World. Working Paper 10140. Cambridge, MA: National Bureau of Economic Research.

Gerigk, J., MacKenzie, I. A., and Ohndorf, M. (2015). A model of benchmarking regulation: revisiting the efficiency of environmental standards. Environ. Resour. Econ. 62, 59-82. doi: 10.1007/s10640-014-9815-7
Goulder, L. H., Long, X., Lu, J., and Morgenstern, R. D. (2019). China's Unconventional Nationwide CO2 Emissions Trading System: The Wide-Ranging Impacts of an Implicit Outputs Subsidy. NBER Working Paper 26537. Cambridge, MA: National Bureau of Economic Research.

Goulder, L. H., and Parry, I. W. H. (2008). Instrument choice in environmental policy. Rev. Env. Econ. Policy 2, 152-174. doi: 10.1093/reep/ren005

Grafton, R. Q., Hannesson, R., Shallard, B., and Sykes, D. (2010). "The economics of allocation in tuna regional fisheries management organizations," in Conservation and Management of Transnational Tuna Fisheries, eds R. Allen, J. Joseph, and D. Squires (Iowa: Wiley- Blackwell), 155-162. doi: 10.1002/ 9780813820262.ch9

Hall, M. A. (1996). On bycatches. Rev. Fish Biol. Fish. 6, 319-352. doi: 10.1007/ bf00122585

Helfand, G. (2013). "Standards," in Encyclopedia of Energy, Natural Resources, and Environmental Economics, Vol. 3, ed. J. F. Shogren (Amsterdam: Elsevier), 217-221.

Hepburn, C. (2006). Regulation by prices, quantities, or both: a review of instrument choice. Oxford Rev. Econ. Pol. 22, 226-247. doi: 10.1093/oxrep/ grj014

Hobday, A. J., and Hartmann, K. (2006). Near real-time spatial management based on habitat predictions for a longline bycatch species. Fish. Manag. Ecol. 13, 365-380. doi: 10.1111/j.1365-2400.2006.00515.x

Holland, D. S. (2018). Collective rights-based fisheries management-a path to ecosystem-based fishery management. Annu. Rev. Resour. Econ. 19, 469-485. doi: 10.1146/annurev-resource-100517-023110

Holland, D. S., and Martin, C. (2019). Bycatch quotas, risk pools, and cooperation in the pacific whiting fishery. Front. Mar. Sci. 6:600. doi: 10.3389/fmars.2019. 00600

Holland, D. S., and Schnier, K. (2006). Individual habitat quotas for fisheries J. Environ. Econ. Man. 5, 72-92. doi: 10.1016/j.jeem.2005.04.005

Holmes, S. J., Bailey, N., Campbell, N., Catarino, R., Barratt, K., Gibb, A., et al. (2011). Using fishery-dependent data to inform the development and operation of a co-management initiative to reduce cod mortality and cut discards. ICES J. Mar. Sci. 68, 1679-1688. doi: 10.1093/icesjms/fsr101

Kotchen, M. J., and Segerson, K. (2019). On the use of group performance and rights for environmental protection and resource management. Proc. Natl. Acad. Sci. U. S. A. 116, 5285-5295. doi: 10.1073/pnas.1802881115

Lent, R., and Squires, D. (2017). Reducing marine mammal bycatch in global fisheries: an economics approach. Deep Sea Res. II 140, 268-277. doi: 10.1016/ j.dsr2.2017.03.005

Little, A. S., Needle, C. L., Hilborn, R., Holland, D. S., and Marshall, C. T. (2015). Real-time spatial management approaches to reduce bycatch and discards: experiences from Europe and the United States. Fish Fish. 16, 576-602. doi: $10.1111 /$ faf. 12080

McKibbin, W. J., and Wilcoxen, P. J. (2002). The role of economics in climate change policy. J. Econ. Perspect. 16, 107-129.

Milner-Gulland, E. J., Garcia, S., Arlidge, W., Bull, J., Charles, T., Dagorn, L., et al. (2018). Translating the terrestrial mitigation hierarchy to marine megafauna bycatch. Fish Fish. 19, 547-561. doi: 10.1111/faf.12273

Mize, J. (2014). Report to the North Pacific Fishery Management Council on the 2013 Bering Sea Pollock Mothership Salmon Savings Incentive Plan. ITEM C7 Mothership Salmon Savings Incentive Plan, April 2014, 16 pages. Anchorage, AL: North Pacific Fishery Management Council.

Montero, J.-P. (2002). Permits, standards and technology innovation. J. Environ. Econ. Manag. 44, 23-44. doi: 10.1006/jeem.2001.1194

Nentjes, A., and Woerdman, E. (2012). Tradable permits versus tradable credits: a survey and analysis. Int. Rev. Environ. Resour. Econ. 6, 1-78. doi: 10.1561/101. 00000047

Parry, I. W. H., and Krupnick, A. J. (2011). Is a Clean Energy Standard a Good Way to Move U.S. Climate Policy Forward?”. Washington, DC: Resources for the Future Issues Brief.

Pascoe, S., Innes, J., Holland, D., Finas, M., Thebaud, O., Townsend, R., et al. (2010). Use of incentive-based management systems to limit bycatch and discarding. Int. Rev. Environ. Resour. Econ. 4, 123-161. doi: 10.1561/101. 00000032

Pizer, W. A. (2002). Combining price and quantity controls to mitigate global climate change. J. Public Econ. 85, 409-434. doi: 10.1016/s0047-2727(01) 00118-9 
Roberts, M. J., and Spence, M. (1976). Effluent charges and licenses under uncertainty. J. Public Econ. 5, 193-208. doi: 10.1016/0047-2727(76)90014-1

Scottish Government (2011). Scottish Government Conservation Credits Scheme: Scheme Rules. Versions 2.1 (11 May 2011). Edinburgh: Scottish Government. Available online at: https://studylib.net/doc/7874209/scottish-governmentconservation-credits-scheme (accessed April 25, 2021)

Segerson, K. (2011). "Policies to reduce stochastic sea turtle bycatch," in Conservation of Pacific Sea Turtles, eds P. H. Dutton, D. Squires, and M. Ahmed (Honolulu: University of Hawaii Press), 370-395. doi: 10.1515/9780824860196021

Shleifer, A. (1985). A theory of yardstick competition. RAND J. Econ. 16, 319-327. doi: $10.2307 / 2555560$

Sovacool, B. K. (2011). The policy challenge of tradable credits: a critical review of eight markets. Energ. Policy 39, 575-585. doi: 10.1016/j.enpol.2010.10.029

Squires, D., Ballance, L. T., Dagorn, L., Dutton, P. H., and Lent, R. (2021). Mitigating bycatch: novel insights to multidisciplinary approaches. Front. Mar. Sci. 8:613285. doi: 10.3389/fmars.2021.613285

Squires, D., and Garcia, S. M. (2018). Economic efficiency and the biodiversity mitigation hierarchy with a focus on marine and fishery issues. Conserv. Biol. 32, 989-997. doi: 10.1111/cobi.13155

Squires, D., Kirkley, J., and Tisdell, C. (1995). Individual transferable quotas as a fishery management tool. Rev. Fish. Sci. 3, 141-169.

Squires, D., Restrepo, V., and Garcia, S. M. (2018). Fisheries bycatch reduction within the least-cost biodiversity mitigation hierarchy: conservatory offsets with an application to sea turtles. Mar. Policy 93, 55-61. doi: 10.1016/j.marpol.2018. 03.018

Stavins, R. (2001). Experience with Market-Based Environmental Policy Regulation. Discussion Paper 01-58. Washington, DC: Resources for the Future.
Sugihara, G., Gruer, J., Haeflinger, K., and Ye, H. (2009). Reducing Chinook Salmon Bycatch with Market-Based Incentives: Individual Tradable Encounter Credits. La Jolla, CA: University of California San Diego.

Van Riel, M., Bush, S., van Zweiten, P., and Mol, A. (2015). Understanding fisheries credit systems: potentials and pitfalls of managing catch efficiency. Fish Fish. 16, 453-470. doi: 10.1111/faf.12066

Wallace, S., Turris, B., Driscoll, J., Bodtker, K., Mose, B., and Munro, B. (2015). Canada's Pacific groundfish trawl habitat agreement: a global in an ecosystem approach to bottom trawl impacts. Mar. Policy 60, 240-248. doi: 10.1016/j. marpol.2015.06.028

Weishaar, S. (2007). CO2 emission allowance allocation mechanisms, allocative efficiency and the environment: a static and dynamic perspective. Eur. J. Law Econ. 24, 29-70. doi: 10.1007/s10657-007-9020-z

Weitzman, M. L. (1974). Prices vs. quantities. Rev. Econ. Stud. 41, 477-491.

Weitzman, M. L. (1978). Optimal rewards for economic regulation. Am. Econ. Rev. $68,683-691$.

WWF (2009). The Scottish Conservation Credits Scheme. Gland: WWF.

Conflict of Interest: The authors declare that the research was conducted in the absence of any commercial or financial relationships that could be construed as a potential conflict of interest.

Copyright ( 2021 Squires, Lent, Dutton, Dagorn and Ballance. This is an open-access article distributed under the terms of the Creative Commons Attribution License (CC BY). The use, distribution or reproduction in other forums is permitted, provided the original author(s) and the copyright owner(s) are credited and that the original publication in this journal is cited, in accordance with accepted academic practice. No use, distribution or reproduction is permitted which does not comply with these terms. 